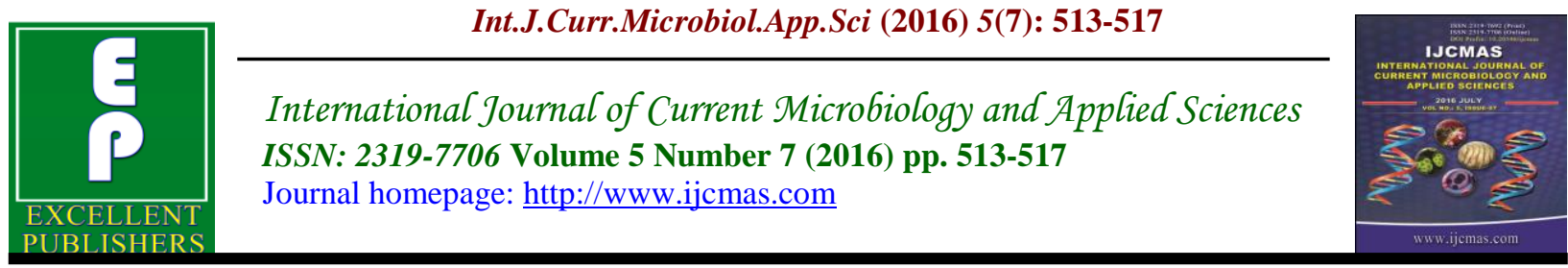

Original Research Article

http://dx.doi.org/10.20546/ijcmas.2016.507.056

\title{
Prevalence of Hepatitis B Surface Antigen (HBsAg) Positivity among General Population in Yavatmal (Maharashtra), India
}

\author{
Pragati Abhimanyu Bulle*, Suchita Tekam, Dilip S. Gedam, \\ Vivek Gujar and Dugesh Deshmukh
}

\author{
Department of Microbiology, Shri Vasantrao Naik Government Medical College, \\ Yavatmal, India \\ *Corresponding author
}

\begin{abstract}
A B S T R A C T
Keywords

Sero-prevalence, Hepatitis B, HBsAg, blood donors, HEPALISA.

Article Info

Accepted:

15 June 2016

Available Online:

10 July 2016

Hepatitis B is one of the major transfusion transmitted infections. It forms a serious health problem globally. Hepatitis B virus (HBV) infection is significant health problem, as it can lead to chronic hepatitis, liver cirrhosis, and hepatic carcinoma. Prevalence of Hepatitis B infection varies across the different geographical areas. Aim of this study was to determine the trend in Hepatitis-B virus infection in general population and to compare the prevalence with that of healthy blood donors. We collected $1 \mathrm{ml}$ of blood samples with all aseptic precautions and tested by HEPALISA. Seroprevalence of HBsAg positive was $1.57 \%$ while in healthy donors it was $0.87 \%$ and in this study majority of sero-positive donors were younger than 40 years. To reduce the prevalence of hepatitis, public awareness, educational and motivational programs, mass immunization programs and Predonation counseling help in decreasing the infection.
\end{abstract}

\section{Introduction}

Hepatitis-B virus infection is a life threatening disease and contributes to a large man power as well as economical loss worldwide. It is a serious and common infectious diseases of the liver affecting millions of people worldwide (Meshram et $a l ., 2015)$. It is caused by hepatitis-B virus which can be transmitted through percutaneous i.e. puncture through the skin and mucosal route i.e. direct contact with mucosal membrane, exposure to infectious blood or blood products, through body fluids. Vertical transmission (from mother to child) of the virus, unsafe sexual intercourse are also important routes for the transmission of the disease (Mohd Akmal et al., 2015).

Hepatitis B virus infection can causes the acute as well as chronic infection. Acute hepatitis implies a condition lasting less than 6 months, culminating either in complete resolution of the liver damage with return to normal liver functions and structure or a rapid progression of the acute injury towards extensive necrosis and a fatal outcome. Chronic hepatitis is defined as sustained inflammatory process in the liver lasting 
longer than 6 months. It can progress towards the cirrhosis of the liver, hapatocellular carcinoma, liver failure \& death. Hepatitis B is $10^{\text {th }}$ leading cause of the death in the world (Chen et al., 2010).

Approximately $30 \%$ of the worlds population or about 2 billion persons have serological evidence of either current or past infection with hepatitis B virus (Prevention of hepatitis B, 2002). A 350-400 millions are chronic carriers and 10 millions of new cases occur annually. Hepatitis B virus infection is estimated to be the cause of $30 \%$ cirrhosis and $53 \%$ of the liver cancer in the world. Approximately $15-40 \%$ of patients with chronic HBV will develop cirrhosis and end stage liver failure or hepatocellular carcinoma in their life time (Chowdhury et al., 2015; Elizabeth et al., 2011; Chowdhury et al., 2001).

However the significance and magnitude of the problem vary from country to country. As per WHO guidelines, Countries are classified on the basis of endemicity of hepatitis-B virus (HBV) infection into high ( $8 \%$ or more), intermediate $(2-7 \%)$, or low (less than 2\%) incidence countries. The prevalence of chronic $\mathrm{HBV}$ infection in India ranges from $2 \%$ to $10 \%$ as shown in different studies. India therefore comes under the intermediate to high endemicity category (Who's Certified, 2002).

The study aimed to determine the trend in Hepatitis-B virus infection in general population and to compare the prevalence with that of healthy blood donors.

\section{Materials and Methods}

This study carried out in department Microbiology Shri Vasantrao Naik Govt Medical College, Yavatmal. This study was conducted from July 2015 to December 2015. We collected $1 \mathrm{ml}$ of blood samples with all aseptic precautions and tested by HEPALISA (manufactured by J.Mitra \& Co Pvt.LTD New Delhi). Simultaneously, we screened the blood donors in the same period for HBsAg. This study was done in healthy donors (18-45 years) attending the blood blank.

\section{Results and Discussions}

A total of 4649 OPD patients were screened for $\mathrm{HBsAg}$, of that 1268 were male while 3381 were female. And seroprevalence of $\mathrm{HbsAg}$ positive was $1.57 \%$.

Table 1 shows that, out of 1268 male patients 28 were positive (2.2\%) and maximum positivity was seen in age group of 30-39 years (10/28). Out of 3381 female patients 45 were positive $(1.33 \%)$ and maximum positivity was seen in age group of 20-29 years (19/45).

Table no 2 shows that, out of the total 5749 blood donors, 5386 were males and 363 were females. None of the females donors were $\mathrm{HBsAg}$ positive, while 50 males were HBsAg positive. Maximum HBsAg positive male donors were in the age group of 26$35 \mathrm{yrs}$. The prevalence of $\mathrm{HBsAg}$ positive was $0.87 \%$ in healthy blood donors.

A large number of studies on the epidemiology of HBV infection have been carried out in this country over the last two decades. There is a wide variation in the prevalence in different regions of the country. These include the sample size, the methodology for assay of HBV serological markers, the age group covered, general population sample versus blood donor and risk population samples, ethinicity and geography of the study population. All these factors have also been shown to influence the prevalence of HBV infection globally. 
Table.1 Age \& Sex wise distribution of clinical OPD patients testing for HBsAg

\begin{tabular}{|l|l|l|l|l|l|l|}
\hline \multirow{2}{*}{$\begin{array}{l}\text { Age of } \\
\text { patients(years) }\end{array}$} & Males & Females & Total & \\
\hline $0-19$ & Number & Positive & Number & Positive & Number & Positive \\
\hline $20-29$ & 125 & 00 & 448 & 00 & 573 & 00 \\
\hline $30-39$ & 354 & 08 & 1258 & 19 & 1612 & 27 \\
\hline $40-40$ & 244 & 10 & 1075 & 12 & 1319 & 22 \\
\hline $50-59$ & 204 & 06 & 112 & 07 & 316 & 13 \\
\hline $60-69$ & 175 & 04 & 246 & 05 & 421 & 09 \\
\hline$>/=70$ & 122 & 00 & 186 & 02 & 308 & 02 \\
\hline Total & 38 & 00 & 56 & 00 & 94 & 00 \\
\hline
\end{tabular}

Table.2 Age and sex wise distribution of HBsAg positive blood donors in blood bank

\begin{tabular}{|l|l|l|l|l|l|l|}
\hline \multirow{2}{*}{$\begin{array}{l}\text { Age of donars } \\
\text { (years) }\end{array}$} & Males & Females & \multicolumn{2}{l|}{ Total } \\
\cline { 2 - 7 } & Number & Positive & Number & Positive & Number & Positive \\
\hline $18-25$ & 1748 & 14 & 128 & 0 & 1876 & 14 \\
\hline $26-35$ & 1958 & 24 & 142 & 0 & 2100 & 24 \\
\hline $36-45$ & 1152 & 09 & 75 & 0 & 1227 & 09 \\
\hline$>45$ & 528 & 03 & 28 & 0 & 556 & 03 \\
\hline Total & 5386 & 50 & 363 & 0 & 5749 & 50 \\
\hline
\end{tabular}

In present study the seroprevalence of HbsAg positive in rural population of Yavatmal region was $1.57 \%$. In Maharashtra prevalence of HBsAg was $2.15 \%$. While, in a population based study of rural population in Birbhum district of West Bengal, with a population of 7653 of all ages and both sexes showed that, prevalence of $\mathrm{HBsAg}$ was $2.97 \%$. In costal Karntaka study shows overall seroprevalence of $\mathrm{HBsAg}$ was observed to be $0.62 \%$ (Karandeep Singh et al., 2009). And the population based meta analysis study by Mohmad et al shows that overall carrier rate is often $4.7 \%$. Like our study, in most of the studies maximum seropositivity was seen after second decade of life because of sexually active age group

In our study seroprevalence of HBsAg was $0.87 \%$ in blood donors. While study done by Rupali et al in Nagpur region seroprevalence of HBsAg was $0.79 \%$ in blood donors.
When the results of this study was compared with those reported from similar blood donors of other countries like Cameroon $11.72 \%$ (Zekeng et al., 1990), Taiwan $4.5 \%$ (Tsai et al., 1991), Ethiopia 14.4\% (Rahlenbeck et al., 1997), Mauritania 20.3\% (Lo et al., 1999), Thailand $4.51 \%$ (Luksamijarulkul et al., 2002), Djibouti 10.4\% (Dray et al., 2005), Mangolia 8.2\% (Tsatsralt-Od et al., 2005), this study showed relatively lower prevalence of the hepatitis-B surface antigen whereas countries like US Community $0.15 \%$ (Kim et al., 2004), showed lower HBsAg positivity in comparison to the present study.

According to India's Drug and Cosmetics Act (1945), each blood unit has to be tested for hepatitis virus infection (Drugs and Cosmetics Act, 1940). The decreasing trend in seroprevalence was noticed over three 
successive years. This may be due to awareness of the disease and modes of prevention may be one reason for the low prevalence declining trends in $\mathrm{HBV}$ infection. Secondly, the implementation of strict predonation counseling and donors selection help in decreasing the infection.

In conclusion, although India lies in intermediate to high endemic category, the prevalence of hepatitis B virus infection is low in Yavatmal region. It is likely that an effective childhood immunization programme will reduce the burden of infection in our country. Simultaneously focus on improving public health measures to prevent disease transmission and decrease the burden of the disease. To reduce the prevalence of transfusion transmitted Hepatitis B, a comprehensive screening of blood donors with recommended methods, strict donor selection criteria, better education of donors and improved prophylactic measures at public level should be implemented to ensure the safe blood donation.

In addition, epidemiologic studies like the present one from different states of India would be helpful to estimate real statistics of hepatitis-B infection in India.

\section{References}

Chen, D.S. 2010. Towards Elimination and Eradication of hepatitis B. $J$. Gastroenterol. Hepatol., 25: 19-25.

Chowdhury, A., Santra, A., Pal, S., Chakravarty, R., et al. 2001. Community based epidemiology study of Hepatitis B virus infection (HBV). Indian J. Gastroenterol., 20(2): A2.

Chowdhury, A. 2015. Epidemiology of Hepatitis B virus infection in India. http://www.hepatitisbannual.org August 5, 2015.
Dray, X., Dray-Spira, R., Bronstein, J.A., Mattera, D. 2005. Prevalence of HIV, hepatitis B and hepatitis C in blood donors in the republic of Djibouti. Med. Trop., 65: 39-42.

Drugs and Cosmetics Act. 1940. (India)

Elizabeth, W., Hwang, Ramsey Cheung. 2011. Global Epidemiology of Hepatitis B virus (HBV) infection. North American J. Medi. Sci., 4(1)

Karandeep Singh, Sudha Bhat, Shamee Shastry. 2009. Trend in seroprevalence of Hepatitis B virus infection among blood donors of coastal Karnataka, India. J. Infect. Dev. Ctries, 3(5): 376-379.

Kim, W.R., Benson, J.T., Therneau, T.M., Torgerson, H.A., Yawn, B.P., Melton, L.J. 3rd. 2004. Changing epidemiology of hepatitis B in a US Community. Hepatol., 39: 811-6.

Lo, B.B., Meymouna, M., Boulahi, M.A., Tew, M., Sow, A., Ba, A., Sow, M.B. 1999. Prevalence of serum markers of Hepatitis B and C virus in blood donors of Nouakchott, Mauritania. Bull. Soc. Pathol. Exot., 92: 83-4.

Luksamijarulkul, P., Thammata, N., Tiloklurs, M. 2002. Seroprevalence of hepatitis B, hepatitis C and human immunodeficiency virus among blood donors, Phitsanulok Regional Blood Center, Thailand. Southeast Asian J. Trop. Med. Public Health, 33: 272-9.

Meshram, R.B., Gedam, D.S. 2015. Prevalence of hepatitis B virus infection in general population of Nagpur region. J. Cont. Med. A Dent., May -August 2015 Volume 3 Issue 2

Mohd Akmal, et al. 2015. Assessment of awareness of Hepatitis B virus infection in the patients attending Nium, Banglore, India. Int. Res. J. Pharmacy, 6(3).

Prevention of hepatitis B in India, An overview. World Health Organization. 
New Delhi 2002.

Rahlenbeck, G.I., Yohannes, G., Molla, K., Reifen, R., Assefa, A. 1997. Infection with HIV, syphilis and hepatitis B in Ethiopia: a survey in blood donors. Int. J. STD AIDS, 8: 261-4.

Tsai, S.J., Chen, C.J., Hsieh, Y.S., Yang, C.S. 1991. Seroprevalence of anti$\mathrm{HCV}$ among voluntary blood donors in Taiwan. Zhonghua Min Guo Wei Sheng Wu Ji Mian Yi Xue Za Zhi., 24: 61-70.

Tsatsralt-Od, B., Takahashi, M., Nishizawa, T., Inoue, J., Ulaankhuu, D., Okamoto,
H. 2005. High prevalence of Hepatitis $\mathrm{B}, \mathrm{C}$ and delta virus infections among donors in Mongolia. Arch. Virol., 150: 2513-28.

Who's Certified [internet]. Prevention of Hepatitis B in India, An overview. World Health Organization, New Delhi 2002.

Zekeng, L., Kaptue, L. 1990. HIV-1 serology and carrier state for HBs and $\mathrm{HBe}$ in blood donors at Yaounde University Hospital Centre, Cameroon. Ann. Soc. Belg. Med. Trop., 70: 49-53.

\section{How to cite this article:}

Pragati Abhimanyu Bulle, Suchita Tekam, Dilip S. Gedam, Vivek Gujar and Dugesh Deshmukh. 2016. Prevalence of Hepatitis B Surface Antigen (HBsAg) Positivity among General Population in Yavatmal (Maharashtra), India. Int.J.Curr.Microbiol.App.Sci. 5(7): 513517. doi: http://dx.doi.org/10.20546/ijcmas.2016.507.056 